\title{
Article \\ Associations between Self-Esteem, Psychological Stress, and the Risk of Exercise Dependence
}

\author{
Frida Austmo Wågan *, Monica Dahle Darvik and Arve Vorland Pedersen
}

check for updates

Citation: Wågan, F.A.; Darvik, M.D.; Pedersen, A.V. Associations between Self-Esteem, Psychological Stress, and the Risk of Exercise Dependence. Int. J. Environ. Res. Public Health 2021, 18, 5577. https://doi.org/10.3390/ ijerph18115577

Academic Editor: Paul B. Tchounwou

Received: 23 April 2021

Accepted: 19 May 2021

Published: 23 May 2021

Publisher's Note: MDPI stays neutral with regard to jurisdictional claims in published maps and institutional affiliations.

Copyright: (c) 2021 by the authors. Licensee MDPI, Basel, Switzerland. This article is an open access article distributed under the terms and conditions of the Creative Commons Attribution (CC BY) license (https:// creativecommons.org/licenses/by/ $4.0 /)$.
Department of Neuromedicine and Movement Science, Norwegian University of Science and Technology (NTNU), N-7491 Trondheim, Norway; monica.darvik@ntnu.no (M.D.D.); arve.v.pedersen@ntnu.no (A.V.P.)

* Correspondence: frida.a.waagan@nord.no
Abstract: Body concerns and stress-related disorders are increasing in the younger population in a wide range of nations. Studies find links between both self-worth, exercise dependence, and selfesteem in relation to stress, but few have considered all three variables in relation to one another. The present study explored whether the co-appearance of high levels of psychological distress, and low levels of self-esteem may be a vulnerability factor for developing exercise dependence by studying the links between self-esteem, psychological stress, and exercise dependence. A standardized cross-sectional questionnaire was completed by 203 regular exercisers attending two gyms (mean age: 35.9 years). The variables self-esteem, psychological distress, and exercise dependence were all significantly correlated with each other, even after weekly exercise amount, age, and gender had been accounted for. Those who exercised for more than $9 \mathrm{~h}$ per week had a significantly higher score on stress and exercise dependence symptoms, and a lower score on self-esteem compared with the remaining groups. One could hypothesize that low self-esteem is a vulnerability factor and high psychological stress a maintenance factor for an exercise-dependent person. It is argued that more focus should be directed toward the negative consequences of excessive exercise.

Keywords: exercise dependence; self-esteem; psychological stress; recreational training; exercise; self-worth

\section{Introduction}

In times of uncertainty and stress, one will seek ways to master the situation [1,2], either in the form of adopting a changed focus and an escape from stressing thoughts and feelings, or through various coping strategies in terms of "behavioral responses that individuals use to manage or tolerate stress" [3], for example by taking control in other lifeareas [4]. Poor self-esteem, whether general or specific, is associated with more maladaptive response patterns and poorer mental health when experiencing stress or difficulties [5,6]. For example, people with poor self-esteem or specific types of self-esteem are found to be more likely to seek coping strategies that distract them from what is perceived as difficult, and to avoid uncomfortable stress and negative emotions with a shift in focus [3,5] often referred to as "avoidance-coping" in the literature [7]. Such coping strategies may include excessive perfectionism in controlling external factors, status, and performance [8,9]; controlling food intake, weight, and body composition [10,11]; using alcohol intoxication for regulating emotions [2]; or controlling exercise and exercise performance, searching for the endorphins and good emotions that come from exercising [4,8], More adaptive or effective coping strategies in reducing emotional distress, and in turn leading to more positive mental health outcomes in the longer term are proposed as adherence to a healthy diet, spending time pursuing hobbies, or spending time outdoors [12].

Moderate amounts of exercise have been demonstrated to reduce both psychological distress [13-15] and depressive symptoms [16], to improve mental health [17], and to increase global and physical self-esteem [18-21]. Furthermore, physical activity (PA) 
and physical fitness are related to lower levels of perceived stress in the general population [22-27]. In a large population-based study including 1.2 million participants, [17] all forms of PA were found to be better for mental health than no PA at all, and the best effects on mental health were found in those who exercised 3-5 times a week for 30-45 min each session. Exercise levels below and above these parameters were linked to more days of poor mental health. Hence, the authors concluded that the dose-response curve has an inverted-U shape rather than a reversed L-shape, as outlined in the extant literature [28,29].

If the focus on exercise or the amount of exercise exceeds a certain level, the risk of physical overload and injury and/or psychological and social difficulties increase, as a result of great physiological and psychological demands on the individual, as well as conflicting time demands within other domains of daily life [1,4,30], Exactly how much exercise constitutes an excessive amount seems to vary between individuals, depending on the purpose of training [30-33], the individual's age, their total stress in life [34-36], their gender [35,37], culture [38,39], exercise experience symptoms [40], and the context the activity is performed within [41,42]. Studies on larger populations have found that more than six hours' weekly exercise increases the risk of exercise dependence [10,32], with a particular risk being associated with exercise levels above 10 to $12 \mathrm{~h}$ per week $[8,36,43]$.

\subsection{Exercise Dependence}

To date, there are two common theories to try to understand exercise dependence: the interactional model [1] and the four-phase model for EA [4]. Both theories emphasize that excessive exercise may function as a strategy for coping with stress deriving from low self-worth and/or lack of mastery in other life areas. There is no standardized definition of exercise addiction [44] but there is a certain consensus that exercise addiction is a multidimensional phenomenon with psychological (e.g., experience of irritation and stress in the absence of exercise), behavioral (e.g., exercise frequency), and/or physiological dimensions (e.g., tolerance for increased amounts of exercise) [45]. Hausenblas and Downs' [32] framework describes exercise addiction as a multidimensional and dysfunctional pattern of exercise, leading to clinically significant reductions in social, physical, and/or psychological functioning and/or persistent psychological stress as a result of the excessive focus on exercise. Their framework builds on seven diagnostic criteria for addictions, inspired by the DSM-IV criteria for substance-misuse disorders [46] proposed by Veale $[47,48]$. Reviews find an average prevalence of exercise addiction between $0.3 \%$ and $3.0 \%$ in normal populations and between $0.9 \%$ and $3.2 \%$ in active populations [48] Also, a large variation is seen across studies due to different uses of measurements and conceptualizations of exercise dependence [49].

It is agreed that people who develop exercise addiction have a vulnerability factor, which may be personal or environmental [4], such as low levels of body-specific self-esteem [50] or perfectionism [8,9]. As with both substance abuse [2] and eating disorders [10], people with low self-esteem are at higher risk of developing unhealthy motives for and addiction to exercise [51]. People who largely build their identity around being an athlete or exerciser, exercising more, and spending more time on exercise are also more vulnerable to developing an addiction to exercise [31,52-54]. In particular, this seems to be the case for those who experience low global self-esteem [55].

\subsection{Self-Esteem and Self-Worth}

Global self-esteem can be seen as the total of positive and negative thoughts and emotions toward the self $[5,56]$, including self-worth, which is about self-acceptance beyond achievements and looks [57], as well as self-evaluations; and specific self-esteem in smaller areas of life, like physical self-esteem, social self-esteem, appearance, and academic selfesteem [21,56-58]. This emphasis further underpins the notion that specific and global self-esteem are two related, but yet different, constructs, with a bidirectional effect on each other [5]. This in turn explains how physical activity may have a positive effect on global self-esteem by mastery and higher levels of physical self-esteem [21]. 


\subsection{Psychological Distress}

Models explaining exercise dependence point to psychological stress as a crucial factor in both the onset and the maintenance of an addiction to exercise $[1,4,59]$. Psychological distress is often described as the subjective feeling of stress inside the individual, occurring when he or she does not have adequate personal resources to meet situational demands effectively [3]. Previous research has found that individual variations in both the weekly PA level and self-esteem are related to fluctuations in psychological stress $[14,60,61]$. Overall, studies examining the effects of physical activity (PA) on both psychological and physiological responses to stress have found PA to lower the stress responses to some extent [62]. The fact that these conclusions are drawn from cross-sectional studies that do not control for all the confounding variables should be mentioned. More recent studies examining the link between PA and stress have found several confounding variables affecting the associations. For instance, Sibley, Hancock, and Bergman (2013) found motivation quality to be crucial to the effect PA had on students' subjective experience of their own psychological distress. Østerås, Haga, and Sigmundsson (2017) found that mindfulness can modify the relationship between PA and reduction in stress levels in adolescents, while Lindwall and Lindgren (2005) found individuals' subjective feeling of mastery in the activity as the most important factor in predicting the stress-reducing effects of PA [63,64].

Nevertheless, even when accounting for moderating variables like motivation and mastery, the risk of exercise dependence is independently associated with both psychological distress [59,65], and low physical [52,54] and global self-esteem [55]. However, to the authors' knowledge, no studies have examined the relationship between psychological distress, self-esteem, exercise dependence, and exercise amount within the same group of individuals. Instead, they have tended to focus on associations between pairs of these constructs. Such an approach may obscure the shared variance between the constructs and mask a potential pathway between self-esteem and stress, resulting in a negative addiction to exercise. The current study investigated the hypothesis that high scores on exercise dependence would be associated with low scores on global self-esteem, high scores on psychological distress, and high weekly training volume-at the same time- in a sample of physically active individuals.

\section{Materials and Methods}

\subsection{Participants}

Two hundred and nine individuals were recruited from two different fitness centers. Six individuals ( 5 men and 1 woman) had incomplete answers and were therefore removed from further analysis (leaving $n=203$ ). The lower age limit for participation was 16 years, and the average age of the sample was 35.9 years $(\mathrm{SD}=\mathrm{x}$; range: $16-71)$. Participants were selected on the basis of a desire to examine a wide and heterogeneous population, where age, life situation, exercise behavior, and motivation vary, in contrast to similar studies that have largely examined student populations $[9,37,66-68]$. Based on the existing literature on the association between training volume and risk of exercise dependence $[8,10,32,36,43,69,70]$, the sample was categorized into three groups based on training volume. Group 1 consisted of those who exercised between 1 and $4.5 \mathrm{~h}$ per week $(\mathrm{n}=93)$, group 2 individuals exercised between 5 and $8 \mathrm{~h}$ per week $(n=85)$, and those in group 3 exercised more than 9 h per week $(n=25)$.

Participants received information about the use of the questionnaires and GDPR and consented by completing the questionnaire.

\subsection{Measures}

A questionnaire consisting of the most widely used Norwegian version of the Rosenberg Self-Esteem Scale (RSES) [60,71,72]; a translated version of the Exercise-Dependence Scale (EDS), previously validated in Norwegian samples [10]; and a translated version of the Perceived Stress Scale (PSS) [73], validated in a Norwegian setting [74] was administered to potential participants by means of easy, accessible paper questionnaires, 
including information on the study, placed at the entrance/reception of the training center together with a safe box for completed questionnaires. No personal data whatsoever were collected in the questionnaire.

The RSES contains 10 items, while the EDS consists of 21 items categorized into seven subscales, each with three items: tolerance, withdrawal, intention effects, lack of control, reduction in other activities, time, and continuance. The PSS consists of 14 items. The internal consistence and reliability of the included measures was examined with Cronbach's alpha. The RSES, the EDS, and the PSS proved to have adequate internal consistency of $0.94,0.96$, and 0.93 , respectively.

The questionnaire also contained questions about exercise behavior; more specifically, these covered exercise volume (weekly exercise hours, rounded to the nearest half hour), exercise motivation, forms of exercise, and intensity of exercise. The questions on exercise volume and exercise behavior were based on standardized activity measures such as the Leisure-Time Exercise Questionnaire (LTEQ) [75], which has been frequently used in previous studies on exercise addiction $[34,50,75]$, and is considered a sufficient target to distinguish between different activity levels in medium and large sample sizes $[28,76]$.

\subsection{Procedure}

Participants were asked about global self-esteem (Rosenberg Self-Esteem Scale, RSES), exercise dependence (Exercise-Dependence Scale, EDS), stress (Perceived Stress Scale, PSS), and exercise behavior through self-reporting in a questionnaire. Participants were asked to mark responses on a scale of 1 (strongly agree) to 4 (strongly disagree) on the RSES, from 1 (never) to 6 (always) on the EDS, and from 1 (never) to 5 (very often) on the PSS. Each response was scored as 1,2,3,4, or 5, and total scores were calculated by adding all values for each scale. Possible composite scores for RSES range from 10 to 40, with higher scores indicating higher global self-esteem [56,71] Five of the statements on the RSES are positively worded (statements 1, 2, 4, 6, 7), whereas the remaining five are formulated negatively (statements $3,5,8,9,10$ ). Scores on positively worded statements are inverted when used for analysis. The same procedure was done with the PSS, as the PSS-scale consists of 14 questions in total, with seven of the questions on the scale positively worded and seven questions negatively worded. Possible composite scores for the EDS range from 21 to 126 , with higher scores indicating higher levels of exercise addiction symptoms. Based on their total scores, participants are classified as asymptomatic ( $\leq 62)$, symptomatic (63-84), or at risk of becoming dependent on exercise $(\geq 85)$. Possible total scores on the PSS range from 14 to 70, with higher scores indicating higher perceived stress [73]. Exercise behavior was recorded by reporting weekly exercise hours (full/half hours), exercise motivation (yes/no), exercise modes for which participants should circle one or two alternatives, and intensity (low/moderate/high). For some of the separate analyses, the sample was divided in three groups based on their weekly exercise amount, respectively between $1-4.5 \mathrm{~h}$ a week, between $5-8.5 \mathrm{~h}$ a week and above $9 \mathrm{~h}$ a week. This ranges were carefully selected based on an earlier review of the studies examining "threshold" training amounts in people with/and without exercise addiction $[10,32,67,69,70]$.

The data collection took place from February to April 2019. Participants received information about the project, and about the use of the data, and consented by completing the questionnaire and posting it in a box behind the front desk of the training centers. No personal data whatsoever were collected. This was done in an attempt to ensure that participants would give more honest answers to the questions, and also as a means of increasing the number of participants in the study.

\subsection{Data Analysis and Processing}

IBM SPSS version 25.0 (IBM, Armonk, NY, USA) was used for all statistical analyses. Hausenblas and Downs' (2002b) scoring manual was used. 


\section{Results}

\subsection{Demographics}

A total of 203 participants (55\% women and $45 \%$ men; mean age 35.9 years old) completed the questionnaire. Information about prevalence of ED (at risk, symptomatic, asymptomatic), weekly exercise amounts and mean scores on the outcome measures are presented in Table 1. Most participants $(59.5 \%, n=121)$ reported themselves as exercising mainly at moderate intensities, $34 \%(n=69)$ reported themselves to be exercising at high intensity, and the remaining $6.5 \%(n=13)$ exercised at low intensities. Resistance training was the most frequent form of exercise $(46 \%, n=92)$, followed by aerobic exercise performed as either running, biking, cross-country skiing, or cross-training $(37.5 \%, n=75)$. Only 16 participants $(7.9 \%)$ exercised with the aim of performing well in a sport, while the remaining 187 participants (92.1\%) reported that they exercised for fitness- and healthrelated reasons.

Table 1. Descriptives and outcome measures by gender.

\begin{tabular}{cccccc}
\hline Variable & Total $(n=203)$ & Men & Women & Range & Z \\
\hline Exercise (Hours /Week) & $5.47(\mathrm{SD}=3.0)$ & $5.9(\mathrm{SD}=2.9)$ & $5.1(\mathrm{SD}=3.0)$ & $1-21$ & $-2.59 * *$ \\
Self-Esteem (RSES) & $31.8(\mathrm{SD}=7.1)$ & $32.7(\mathrm{SD}=7.25)$ & $31.1(\mathrm{SD}=6.9)$ & $10-40$ & -1.53 \\
$\quad$ Stress (PSS) & $34.5(\mathrm{SD}=10.8)$ & $32.1(\mathrm{SD}=9.8)$ & $36.5(\mathrm{SD}=11.2)$ & $14-70$ & $-2.85 * *$ \\
Exercise Dependence & $54.4(\mathrm{SD}=21.8)$ & $54.5(\mathrm{SD}=20.9)$ & $54.0(\mathrm{SD}=22.4)$ & $21-126$ & -0.33 \\
$\quad($ EDS & & & & \\
\hline
\end{tabular}

** Significant $p \leq 0.005$.

Based on the EDS criteria [32] 20 participants (9.9\%) were classified as at risk, 38 participants $(18.7 \%)$ as symptomatic, and the remaining 145 participants $(71.2 \%)$ as asymptomatic. No gender differences were apparent in the numbers of participants classified as at risk of developing exercise dependence.

\subsection{Relationships between Self-Esteem, Weekly Exercise, Stress, and Exercise Dependence}

Spearman's Rho correlations were computed between the variables self-esteem, weekly exercise, stress, and exercise-dependence symptoms (see Table 2). All outcome measures correlated significantly with each other $(p \leq 0.001)$. There was a negative correlation between self-esteem and EDS score, as seen in Figure 1, whereas a positive association was found between stress and EDS score, as seen in Figure 2, indicating that individuals with the highest EDS scores experienced more stress and lower levels of self-esteem than those with lower scores on the EDS. The EDS subcategories "withdrawal effect", and "reduction in other activities" (items $5,11,19)$ had the strongest correlations $(r \leq 0.53)$ with overall scores on both self-esteem (RSES) and stress (PSS).

Table 2. Correlation analyses.

\begin{tabular}{|c|c|c|c|c|}
\hline & Self-Esteem (RSES) & Exercise Dependence (EDS) & Weekly Training Hours & Stress (PSS) \\
\hline (RSES) & 1 & & & \\
\hline$(\mathrm{EDS})$ & $-0.597^{* *}$ & 1 & & \\
\hline Weekly Training Hours & $-0.338^{* *}$ & $0.566^{* *}$ & 1 & \\
\hline (PSS) & $-0.781^{* *}$ & $0.567^{* *}$ & $0.298^{* *}$ & 1 \\
\hline
\end{tabular}

** Significant correlation $p \leq 0.001$. 


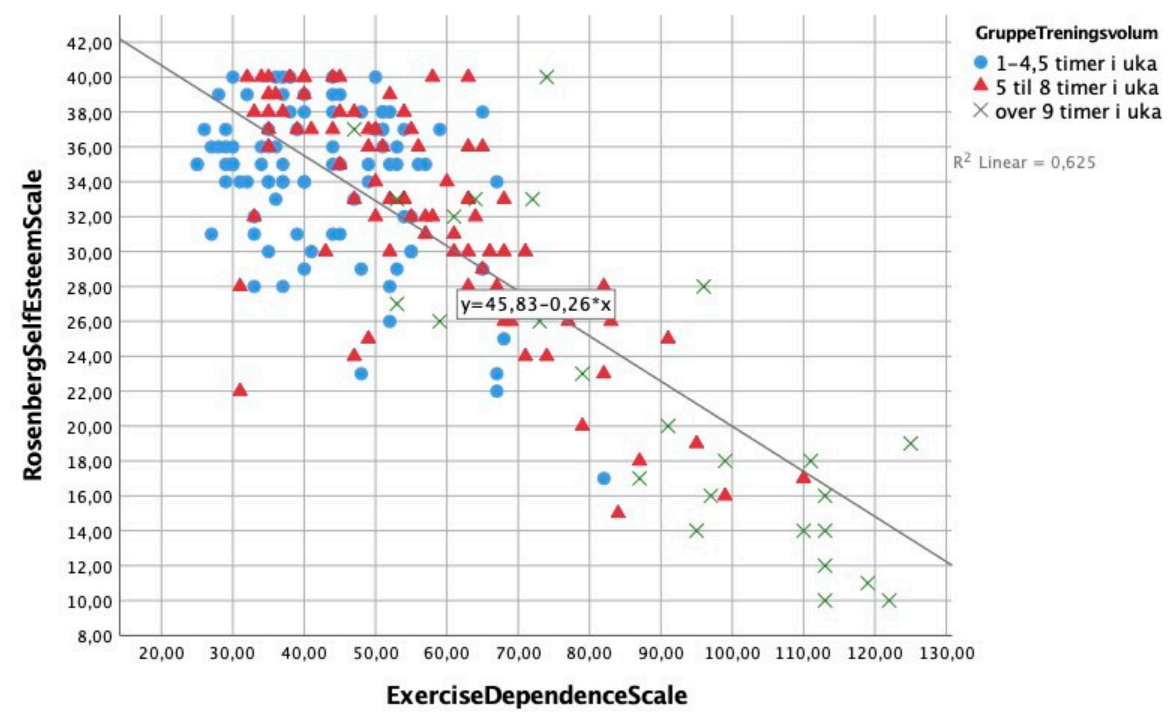

Figure 1. Graphic representation of the association between self-esteem (RSES-score) and exercisedependence symptoms, by three different levels of weekly exercise hours.

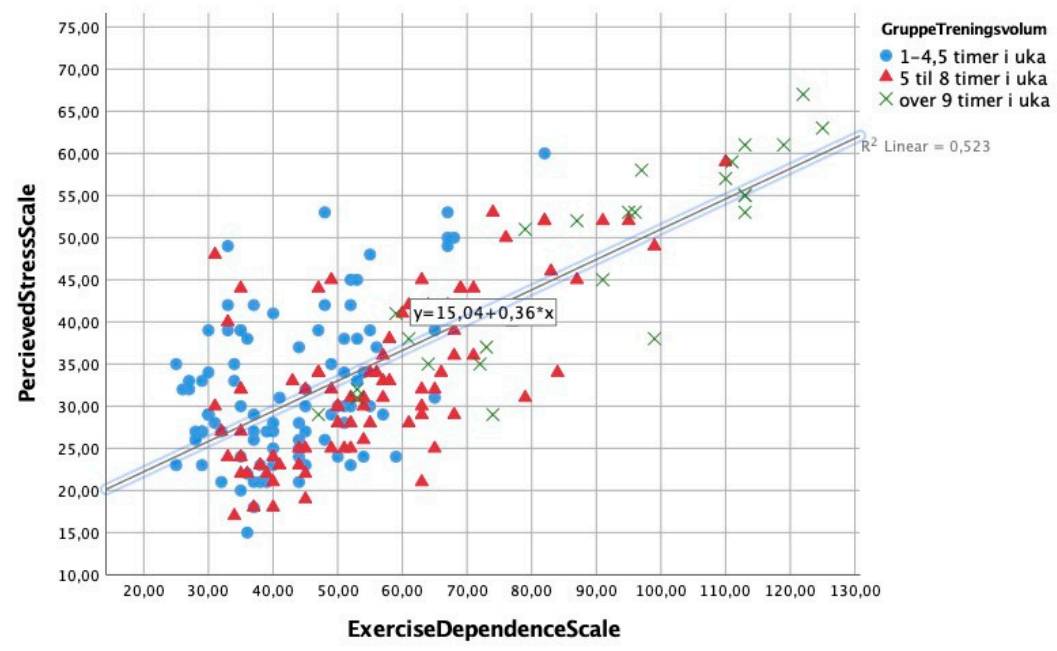

Figure 2. Graphic representation of the association between stress (PSS-score) and exercisedependence symptoms, by three different levels of weekly exercise hours.

\subsection{Group Differences in Exercise-Dependence Symptoms, Stress, and Self-Esteem}

Significant differences between groups were observed for total scores on self-esteem, psychological distress, and exercise-dependence symptoms when we split the data by three different levels of weekly exercise times into $1-4.5 \mathrm{~h}, 5-8.5 \mathrm{~h}$, and over $9 \mathrm{~h}$ per week. (see Table 3). Further analysis revealed no significant variance between participants in the $1-4.5 \mathrm{~h}$ and the $5-8.5 \mathrm{~h}$ per week groups. When the outcome scores for participants exercising more than $9 \mathrm{~h}$ per week were compared to the $1-4.5 \mathrm{~h}$ per week and the $5-8.5 \mathrm{~h}$ per week groups separately, the $>9 \mathrm{~h}$ per week groups had significantly lower scores on self-esteem and higher scores on exercise-dependence symptoms and psychological distress than the remaining groups in all analyses.

Table 3. Between-group differences in self-esteem, stress, and exercise-dependence scores.

\begin{tabular}{lccc}
\hline & $\mathbf{1 - 4 . 5} \mathbf{h} /$ Week $(\boldsymbol{n}=\mathbf{9 3})$ & $\mathbf{5 - 8 . 5} \mathbf{h} /$ Week $(\boldsymbol{n}=\mathbf{8 5})$ & $\mathbf{> 9} \mathbf{h} / \mathbf{W e e k}(\boldsymbol{n}=\mathbf{2 5})$ \\
\hline RSES (Mean Score, SD) & $34.2(\mathrm{SD}=4.4)$ & $32.2(\mathrm{SD}=6.4)$ & $21.9(\mathrm{SD}=9.0)$ \\
EDS (Mean Score, SD) & $42.9(\mathrm{SD}=11.7)$ & $56.4(\mathrm{SD}=17.2)$ & $89.6(\mathrm{SD}=24.4)$ \\
PSS (Mean Score, SD) & $31.9(\mathrm{SD}=8.9)$ & $33.6(\mathrm{SD}=9.7)$ & $47.5(\mathrm{SD}=11.9)$ \\
\hline
\end{tabular}




\subsection{Age and Gender Differences for Exercise-Dependence Symptoms, Stress, and Self-Esteem}

Spearman's Rho correlations were computed between age, self-esteem, weekly exercise, stress, and exercise-dependence symptoms. A Kruskal-Wallis test between the three different exercise volumes split by gender was performed to test whether the mean scores on self-esteem, psychological distress, and exercise dependence differed between genders with varying amounts of weekly exercise. Age correlated significantly $(p \leq 0.001)$ with total exercise amount $(r=0.28)$ and total score on the EDS $(r=0.50)$, but no correlations were seen between age and psychological distress or self-esteem. After adjusting the significance level on the Kruskal-Wallis test with Bonferroni correction, only the scores on psychological distress $(\mathrm{z}=-0.28)$ and weekly exercise volume $(\mathrm{z}=-0.259)$ differed between genders within the three exercise groups. Looking at the total sample (i.e., not split by weekly exercise volume), only psychological distress differed significantly between genders, but the difference was small to moderate (see Table 1).

\section{Discussion}

The aim of our study was to examine if the combination of low levels of self-esteem and high levels of psychological distress was related to high scores on the measures of exercise-dependence symptoms, to further predict risk factors for developing an addiction to exercise. In line with our main hypothesis, and based on the theoretical frameworks for understanding Exercise Dependence by Freimuth et al. (2011), and Szabo and Egorov (2013) [1,4], we found that higher levels of psychological distress and low levels of selfesteem were related to higher scores on measures of exercise dependence, as well as higher amounts of weekly exercise hours. More specifically, self-esteem had a significant negative correlation with both the Exercise-Dependence score and total weekly exercise volume, while psychological distress had a significant positive correlation with the ExerciseDependence score and the total weekly exercise duration. All correlations were significant after accounting for age and gender, meaning there is a universal trend in both genders, in that those who had weekly exercise volumes above $9 \mathrm{~h}$ had significantly higher scores on exercise dependence and psychological distress, as well as lower scores on self-esteem compared to individuals exercising fewer than $9 \mathrm{~h}$ each week. Women generally had significantly higher scores on stress and a lower volume of weekly exercise. However, the differences were small to moderate. No gender differences were seen in either selfesteem or exercise-dependence symptoms.

The present findings expand previous research by showing that low self-esteem $[52,54]$ and high levels of psychological distress $[59,65]$ are co-existent in individuals with a high risk for developing exercise dependence. Such findings are also in line with qualitative studies on eating disorders $[10,11]$ and exercise dependence $[30,77]$ reporting excessive control over food or exercise as a coping strategy for handling psychological distress and a sense of inferiority compared to others. More specifically, the existing literature has reported that negative thoughts about one's physical appearance is a source of negative stress, especially in young adults [78-81]. Excessive exercise as a means of attaining the perceived standards/ideals of what a body should look like may in part explain the reported correlations between low self-esteem, high weekly exercise-volume, and high scores on exercise-dependence symptoms. On the other hand, this cannot explain why global measures of self-esteem that measure general feelings of self-worth-and not bodily self-esteem or physical appearance-also seem to correlate with psychological distress and exercise dependence in the present sample of individuals, as well as in previous studies $[33,80,82]$.

We found that both exercise-dependence symptoms and weekly exercise volume declined with age, as in earlier studies [34]. However, even after adjusting for both gender and age, the correlation between self-esteem, risk for exercise dependence, and psychological stress remained significant in all analyses. This stands somewhat in contrast to previous research that has reported both gender and age to influence scores on measures for selfesteem [79] and exercise dependence [34], prompting the authors to identify both gender 
and age as crucial factors for the onset of eating disorders [30], exercise dependence [34], or a combination of the two [10,11]. The discrepancy between the present and previous findings may be due to different ages of the studied populations across studies $[34,79]$ as well as cultural, contextual, or individual variations $[39,40]$. The participants in our study exercised more than what other studies argue to be "an optimal volume of exercise" for the "normal population", with a weekly exercise time of 5.4 h [17], 22-40 METS [83], or in a range from 2.5 to $7.5 \mathrm{~h}$ [84]. However, when compared with other studies examining exercise dependence $[38,43,69,70]$, the mean amount of weekly exercise hours in the present sample is similar to previous findings. Many researchers have attempted to establish a "limit" for when exercise gets "unhealthy" and "addictive" [32,68], despite the rather similar mean exercise volumes per week in the existing literature, there is still no consensus about such a limit. Considering limits proposed in previous studies, such as 5-6 h/week $[32,69,70]$ and 9-10 h/week $[8,36,38,43]$, we chose to split the present sample into three different exercise groups (1-4.5 h per week, $5-8.5 \mathrm{~h}$ per week, and more than $9 \mathrm{~h}$ per week). In line with earlier results, we found that the group that exercised for more than $9 \mathrm{~h}$ /week differed significantly from the two remaining groups, in terms of exercise-dependence symptoms, self-esteem, and psychological distress parameters. In line with Chekroud's et al. (2018) findings from examining 1.1 million individuals, our study supports the hypothesis that the relationship between exercise volume and health benefits looks more like an inverted $U$, with an optimal point before the effects slowly diminishes as the exercise volume increases [17]. Thus, our results do not support the assumption that has dominated the literature until rather recently $[28,29]$ that the relation between the amount of exercise, and the physical- and mental-health outcomes form can be depicted as an inverted-L curve.

The present study found a prevalence of individuals at risk for exercise dependence $(9.9 \%)$ which is comparable to previous research conducted in sports and exercise settings $[32,70,85,86]$, while being higher than in studies conducted on larger "normal" populations, for example, representative populations for one country [44,87]. Furthermore, cultural and national differences have also been reported to play a role in terms of prevalence of exercise dependence [85] as well as self-esteem and the cultural emphasis on appearance and body shape $[88,89]$, which must be taken into consideration when comparing our study to others.

Although our results to some degree expand the extant literature, limitations exist. Firstly, self-reported data on weekly exercise volume may have intrinsic limitations, such as social desirability [90]. Secondly, although this is one of the relatively few studies to examine the impact of both self-esteem and psychological distress on exercise dependence, the present results of this study are based on cross-sectional data, not observations of changes in stress and self-esteem due to changes in exercise volume, or exercise-dependence symptoms. Use of longitudinal data tends to provide better understanding, allowing attributions regarding the cause or directional effects. A major limitation of our study was that exercise motivation included only these two categories: desire to improve performance in sports/races and health- and fitness-related reasons, based on the findings of earlier studies, showing that exercise for health reasons is found to be related to improvements in body image $[18,89,91]$ and self-esteem $[18,64]$ during exercise interventions or regular physical activity. Other studies find that motives such as exercising to lose weight, to improve one's appearance, or to avoid the feeling of inferiority compared to others are related to reductions in self-esteem $[10,33,92]$. Hence, we should have included a third category addressing appearance-based exercise motivation to separate those exercising for health, and those exercising for appearance. The present results therefore need to be seen in light of studies reporting activity motivation $[83,92,93]$ and context $[41,42]$ as crucial for determining the psychological effects of that specific activity on self-esteem. Yet further research is needed, addressing the role exercise motivation plays for the relationship between exercise dependence, psychological distress, and self-esteem. 
Another aspect to take into consideration is that the EDS is a screening device developed to distinguish among at-risk, nondependent symptomatic, and nondependent asymptomatic individuals [94], and not a diagnostic system. Even if variables correlated with increased risk of developing exercise dependence may, in part, explain why some develop and maintain an addiction to exercise, clinical interviews by qualified personnel are needed to understand the mechanisms behind exercise dependence for each individual [87]. The present results enable no such diagnosing, nor do they in any other way suggest more severe mental illness. Furthermore, our research was limited by the methodology of the present study itself, as cross-sectional questionnaires are seen as inappropriate when talking about causal relationships between phenomena and related underlying mechanisms. Finally, research is needed on more of the mediating mechanisms underlying changes in self-esteem, psychological distress, and exercise behavior across the subject's lifespan, such as the context of the activity, or the societal impact.

\section{Conclusions}

In summary, our study makes several significant contributions to the exercise-dependence literature. First by expanding the excitant literature by showing a co-existence of low self-esteem and high levels of psychological distress in individuals with a high risk for developing exercise dependence. Second by showing a further co-existence between both low self-esteem, high levels of psychological distress and high risk for developing exercise dependence in individuals with weekly training amounts beyond $9 \mathrm{~h}$ a week, even after adjusting for gender and age. Third, by supporting recent studies demonstrating an inverted U-relationship between weekly training amounts and mental health. Due to the limitations in the study, it is a first step in understanding variations in the varying effect of exercise on both stress and self-esteem.

Author Contributions: Conceptualization, F.A.W., A.V.P. and M.D.D.; methodology, F.A.W. and M.D.D.; software, F.A.W. and M.D.D.; validation, F.A.W., A.V.P. and M.D.D.; formal analysis, F.A.W.; investigation, F.A.W.; writing—original draft preparation, F.A.W.; writing—review and editing, A.V.P. and M.D.D.; supervision, A.V.P. and M.D.D.; project administration, F.A.W. All authors have read and agreed to the published version of the manuscript.

Funding: This research received no external funding.

Institutional Review Board Statement: Not applicable.

Informed Consent Statement: Informed consent was obtained from all subjects involved in the study. No personal data whatsoever were collected; thus, further formal approval was not required as per national regulations. The Norwegian Centre for Research Data, the national regulating body, state the following on their website: "If you are only going to collect anonymous data, then the project should not be notified to NSD". https:/ / www.nsd.no/en/data-protection-services/notificationform-for-personal-data (accessed on 20 April $2021{ }^{*}$ ). * However, the link also was accessed in October 2018, before the data collection started.

Data Availability Statement: The data presented in this study are available upon reasonable request from the corresponding author.

Acknowledgments: The authors thank the study participants for their participation.

Conflicts of Interest: The authors declare no conflict of interest.

\section{References}

1. Egorov, A.Y.; Szabo, A.D. The exercise paradox: An interactional model for a clearer conceptualization of exercise addiction. J. Behav. Addict. 2013, 2, 199-208. [CrossRef]

2. Silverstone, P.H.; Salsali, M. Low self-esteem and psychiatric patients: Part I-The relationship between low self-esteem and psychiatric diagnosis. Ann. Gen. Psychiatry 2003, 2, 2. [CrossRef]

3. Lazarus, R.S. Psychological Stress and the Coping Process; McGraw-Hill: New York, NY, USA, 1966.

4. Freimuth, M.; Moniz, S.; Kim, S.R. Clarifying Exercise Addiction: Differential Diagnosis, Co-occurring Disorders, and Phases of Addiction. Int. J. Environ. Res. Public Health 2011, 8, 4069-4081. [CrossRef] [PubMed] 
5. Rosenberg, M.; Schooler, C.; Schoenbach, C.; Rosenberg, F. Global Self-Esteem and Specific Self-Esteem: Different Concepts, Different Outcomes. Am. Sociol. Rev. 1995, 60, 141. [CrossRef]

6. Bandura, A. Self-Efficacy: The Exercise of Control; Freeman: New York, NY, USA, 1997.

7. Taylor, S.E.; Stanton, A.L. Coping Resources, Coping Processes, and Mental Health. Annu. Rev. Clin. Psychol. $2007,3,377-401$. [CrossRef]

8. Hagan, A.L.; Hausenblas, H.A. The relationship between exercise dependence symptoms and perfectionism. Am. J. Health Stud. 2003, 18, 133.

9. Costa, S.; Hausenblas, H.A.; Oliva, P.; Cuzzocrea, F.; Larcan, R. Maladaptive perfectionism as mediator among psychological control, eating disorders, and exercise dependence symptoms in habitual exerciser. J. Behav. Addict. 2016, 5, 77-89. [CrossRef] [PubMed]

10. Bratland-Sanda, S.; Martinsen, E.W.; Rosenvinge, J.H.; Rø, Ø.; Hoffart, A.; Sundgot-Borgen, J. Exercise dependence score in patients with longstanding eating disorders and controls: The importance of affect regulation and physical activity intensity. Eur. Eat. Disord. Rev. 2011, 19, 249-255. [CrossRef]

11. Bratland-Sanda, S.; Sundgot-Borgen, J.; Rø, Ø.; Rosenvinge, J.H.; Hoffart, A.; Martinsen, E.W. “I'm not physically active-I only go for walks": Physical activity in patients with longstanding eating disorders. Int. J. Eat. Disord. 2009, 43, 88-92. [CrossRef] [PubMed]

12. Fullana, M.A.; Hidalgo-Mazzei, D.; Vieta, E.; Radua, J. Coping behaviors associated with decreased anxiety and depressive symptoms during the COVID-19 pandemic and lockdown. J. Affect. Disord. 2020, 275, 80-81. [CrossRef] [PubMed]

13. Haugland, S.; Wold, B.; Torsheim, T. Relieving the Pressure? The Role of Physical Activity in the Relationship between SchoolRelated Stress and Adolescent Health Complaints. Res. Q. Exerc. Sport 2003, 74, 127-135. [CrossRef] [PubMed]

14. Moljord, I.E.O.; Eriksen, L.; Moksnes, U.K.; Espnes, G.A. Stress and Happiness among Adolescents with Varying Frequency of Physical Activity. Percept. Mot. Skills 2011, 113, 631-646. [CrossRef]

15. Gerber, M.; Pühse, U. “Don't crack under pressure!"-Do leisure time physical activity and self-esteem moderate the relationship between school-based stress and psychosomatic complaints? J. Psychosom. Res. 2008, 65, 363-369. [CrossRef] [PubMed]

16. Searle, A.; Calnan, M.; Lewis, G.; Campbell, J.; Taylor, A.; Turner, K. Patients' views of physical activity as treatment for depression: A qualitative study. Br. J. Gen. Pract. 2011, 61, e149-e156. [CrossRef] [PubMed]

17. Chekroud, S.R.; Gueorguieva, R.; Zheutlin, A.B.; Paulus, M.; Krumholz, H.M.; Krystal, J.H.; Chekroud, A.M. Association between physical exercise and mental health in 1.2 million individuals in the USA between 2011 and 2015: A cross-sectional study. Lancet Psychiatry 2018, 5, 739-746. [CrossRef]

18. Haugen, T.; Ommundsen, Y.; Seiler, S. The Relationship between Physical Activity and Physical Self-Esteem in Adolescents: The Role of Physical Fitness Indices. Pediatr. Exerc. Sci. 2013, 25, 138-153. [CrossRef] [PubMed]

19. Ekeland, E.; Heian, F.; Hagen, K.B.; Abbott, J.M.; Nordheim, L. Exercise to improve self-esteem in children and young people. Cochrane Database Syst. Rev. 2004, 1, CD003683. [CrossRef]

20. Ekeland, E.; Heian, F.; Hagen, K.B. Can exercise improve self esteem in children and young people? A systematic review of randomised controlled trials * Commentary. Br. J. Sports Med. 2005, 39, 792-798. [CrossRef]

21. Fox, K.R. Self-esteem, self-perceptions and exercise. Int. J. Sport Psychol. 2000, 31, 228-240.

22. Gerber, M.; Lindwall, M.; Lindegård, A.; Börjesson, M.; Jonsdottir, I.H. Cardiorespiratory fitness protects against stress-related symptoms of burnout and depression. Patient Educ. Couns. 2013, 93, 146-152. [CrossRef]

23. Norris, R.; Carroll, U.; Cochrane, R. The effects of aerobic and anaerobic training on fitness, blood pressure, and psychological stress and well-being. J. Psychosom. Res. 1990, 34, 367-375. [CrossRef]

24. Norris, R.; Carroll, D.; Cochrane, R. The effects of physical activity and exercise training on psychological stress and well-being in an adolescent population. J. Psychosom. Res. 1992, 36, 55-65. [CrossRef]

25. Rimmele, U.; Zellweger, B.C.; Marti, B.; Seiler, R.; Mohiyeddini, C.; Ehlert, U.; Heinrichs, M. Trained men show lower cortisol, heart rate and psychological responses to psychosocial stress compared with untrained men. Psychoneuroendocrinology 2007, 32, 627-635. [CrossRef]

26. Steptoe, A.; Edwards, S.; Moses, J.; Mathews, A. The effects of exercise training on mood and perceived coping ability in anxious adults from the general population. J. Psychosom. Res. 1989, 33, 537-547. [CrossRef]

27. Steptoe, A.; Butler, N. Sports participation and emotional wellbeing in adolescents. Lancet 1996, 347, 1789-1792. [CrossRef]

28. Pate, R.R.; Pratt, M.; Blair, S.N.; Haskell, W.L.; Macera, C.A.; Bouchard, C.; Buchner, D.; Ettinger, W.; Heath, G.W.; King, A.C.; et al. Physical Activity and Public Health: A recommendation from the Centers for Disease Control and Prevention and the American College of Sports Medicine. JAMA 1995, 273, 402-407. [CrossRef] [PubMed]

29. Hamer, M.; Stamatakis, E.; Steptoe, A. Dose-response relationship between physical activity and mental health: The Scottish Health Survey. Br. J. Sports Med. 2009, 43, 1111-1114. [CrossRef] [PubMed]

30. Cox, R.; Orford, J. A qualitative study of the meaning of exercise for people who could be labelled as 'addicted' to exercise -Can 'addiction' be applied to high frequency exercising? Addict. Res. Theory 2004, 12, 167-188. [CrossRef]

31. Menczel, Z.; Griffiths, M.D.; Vingender, I.; Eisinger, A.; Farkas, J.; Magi, A.K.; Mervo, B.F.; Kökönyei, G.; Demetrovics, Z. Exercise Dependence in Amateur Competitors and Non-Competitor Recreational Exercisers. Int. J. Ment. Health Addict. 2017, 15, 580-587. [CrossRef] 
32. Hausenblas, H.A.; Downs, D.S. How much is Too Much? The Development and Validation of the Exercise Dependence Scale. Psychol. Health 2002, 17, 387-404. [CrossRef]

33. Smith, D.K.; Hale, B.D.; Collins, D. Measurement of exercise dependence in bodybuilders. J. Sports Med. Phys. Fit. 1998, 38, 66-74.

34. Costa, S.; Hausenblas, H.A.; Oliva, P.; Cuzzocrea, F.; Larcan, R. The role of age, gender, mood states and exercise frequency on exercise dependence. J. Behav. Addict. 2013, 2, 216-223. [CrossRef] [PubMed]

35. Edmunds, J.; Ntoumanis, N.; Duda, J.L. Examining Exercise Dependence Symptomatology from a Self-determination Perspective. J. Health Psychol. 2006, 11, 887-903. [CrossRef] [PubMed]

36. Lichtenstein, M.B.; Christiansen, E.; Elklit, A.; Bilenberg, N.; Støving, R.K. Exercise addiction: A study of eating disorder symptoms, quality of life, personality traits and attachment styles. Psychiatry Res. 2014, 215, 410-416. [CrossRef]

37. Cook, B.; Hausenblas, H.A.; Rossi, J. The moderating effect of gender on ideal-weight goals and exercise dependence symptoms. J. Behav. Addict. 2013, 2, 50-55. [CrossRef]

38. Lichtenstein, M.B.; Jensen, T.T. Exercise addiction in CrossFit: Prevalence and psychometric properties of the Exercise Addiction Inventory. Addict. Behav. Rep. 2016, 3, 33-37. [CrossRef]

39. Lichtenstein, M.B.; Emborg, B.; Hemmingsen, S.D.; Hansen, N.B. Is exercise addiction in fitness centers a socially accepted behavior? Addict. Behav. Rep. 2017, 6, 102-105. [CrossRef] [PubMed]

40. Mayolas-Pi, C.; Simón-Grima, J.; Peñarrubia-Lozano, C.; Munguía-Izquierdo, D.; Moliner-Urdiales, D.; Legaz-Arrese, A. Exercise addiction risk and health in male and female amateur endurance cyclists. J. Behav. Addict. 2017, 6, 74-83. [CrossRef]

41. Kleppang, A.L.; Hartz, I.; Thurston, M.; Hagquist, C. The association between physical activity and symptoms of depression in different contexts-A cross-sectional study of Norwegian adolescents. BMC Public Health 2018, 18, 1368. [CrossRef]

42. Doré, I.; O'Loughlin, J.L.; Beauchamp, G.; Martineau, M.; Fournier, L. Volume and social context of physical activity in association with mental health, anxiety and depression among youth. Prev. Med. 2016, 91, 344-350. [CrossRef]

43. Meulemans, S.; Pribis, P.; Grajales, T.; Krivak, G. Gender Differences in Exercise Dependence and Eating Disorders in Young Adults: A Path Analysis of a Conceptual Model. Nutrients 2014, 6, 4895-4905. [CrossRef]

44. Mónok, K.; Berczik, K.; Urbán, R.; Szabo, A.; Griffiths, M.D.; Farkas, J.; Magi, A.; Eisinger, A.; Kurimay, T.; Kökönyei, G.; et al. Psychometric properties and concurrent validity of two exercise addiction measures: A population wide study. Psychol. Sport Exerc. 2012, 13, 739-746. [CrossRef]

45. Birche, J.; Griffiths, M.D.; Kasos, K.; Demetrovics, Z.; Szabo, A. Exercise addiction and personality: A two-decade systematic review of the empirical literature (1995-2016). Balt. J. Sport Health Sci. 2017, 3, 19-33. [CrossRef]

46. American Psychiatric Association. Diagnostic and Statistical Manual for Mental Disorders, 4th ed.; American Psychiatric Publishing: Washington, DC, USA, 2000.

47. Veale, D.C. Exercise Dependence. Br. J. Addict. 1987, 82, 735-740. [CrossRef]

48. Veale, D.C. Does primary exercise dependence really exist? In Exercise Addiction: Motivation for Participation in Sport and Exercise; British Psychological Society: London, UK, 1995; pp. 71-75.

49. Allegre, B.; Souville, M.; Therme, P.; Griffiths, M. Definitions and measures of exercise dependence. Addict. Res. Theory 2006, 14, 631-646. [CrossRef]

50. Bamber, D.; Cockerill, I.M.; Carroll, D. The pathological status of exercise dependence. Br. J. Sports Med. 2000, $34,125-132$. [CrossRef]

51. Silberstein, L.R.; Striegel-Moore, R.H.; Timko, C.; Rodin, J. Behavioral and psychological implications of body dissatisfaction: Do men and women differ? Sex Roles 1988, 19, 219-232. [CrossRef]

52. Lichtenstein, M.B.; Hinze, C.J.; Emborg, B.; Thomsen, F.; Hemmingsen, S.D. Compulsive exercise: Links, risks and challenges faced. Psychol. Res. Behav. Manag. 2017, 10, 85-95. [CrossRef]

53. Brewer, B.W.; Van Raalte, J.L.; Linder, D.E. Athletic identity: Hercules' muscles or Achilles heel? Int. J. Sport Psychol. 1993, 24, 237-254.

54. Murray, A.L.; McKenzie, K.; Newman, E.; Brown, E. Exercise identity as a risk factor for exercise dependence. Br. J. Health Psychol. 2012, 18, 369-382. [CrossRef]

55. Groves, M.; Biscomb, K.; Nevill, A.; Matheson, H. Exercise dependence, self-esteem and identity reinforcement: A comparison of three universities in the United Kingdom. Sport Soc. 2008, 11, 59-73. [CrossRef]

56. Avison, W.R.; Rosenberg, M. Conceiving the Self. Can. J. Sociol. 1981, 6, 212-214. [CrossRef]

57. Shavelson, R.J.; Hubner, J.J.; Stanton, G.C. Self-Concept: Validation of Construct Interpretations. Rev. Educ. Res. 1976, 46, 407-441. [CrossRef]

58. Covington, M.V. Making the Grade: A Self-Worth Perspective on Motivation and School Reform; Cambridge University Press: Cambridge, UK, 1992.

59. Szabo, A. The impact of exercise deprivation on well-being of habitual exercises. Aust. J. Sci. Med. Sport 1995, $27,68-77$.

60. Moksnes, U.K.; Moljord, I.E.; Espnes, G.A.; Byrne, D.G. The association between stress and emotional states in adolescents: The role of gender and self-esteem. Personal. Individ. Differ. 2010, 49, 430-435. [CrossRef]

61. Moksnes, U.K.; Moljord, I.E.; Espnes, G.A.; Byrne, D.G. Leisure time physical activity does not moderate the relationship between stress and psychological functioning in Norwegian adolescents. Ment. Health Phys. Act. 2010, 3, 17-22. [CrossRef]

62. Salmon, P. Effects of physical exercise on anxiety, depression, and sensitivity to stress. Clin. Psychol. Rev. 2001, $21,33-61$. [CrossRef] 
63. Østerås, B.; Sigmundsson, H.; Haga, M. Physical Fitness Levels Do Not Affect Stress Levels in a Sample of Norwegian Adolescents. Front. Psychol. 2017, 8, 2176. [CrossRef] [PubMed]

64. Lindwall, M.; Lindgren, E.-C. The effects of a 6-month exercise intervention programme on physical self-perceptions and social physique anxiety in non-physically active adolescent Swedish girls. Psychol. Sport Exerc. 2005, 6, 643-658. [CrossRef]

65. Guidi, J.; Clementi, C.; Grandi, S. Psychological distress and personality characteristics among individuals with primary exercise dependence. Riv. Psichiatr. 2013, 48, 121-129.

66. Downs, D.S.; Savage, J.S.; DiNallo, J.M. Self-Determined to Exercise? Leisure-Time Exercise Behavior, Exercise Motivation, and Exercise Dependence in Youth. J. Phys. Act. Health 2013, 10, 176-184. [CrossRef]

67. Downs, D.S.; Hausenblas, H.A.; Nigg, C.R. Factorial Validity and Psychometric Examination of the Exercise Dependence Scale-Revised. Meas. Phys. Educ. Exerc. Sci. 2004, 8, 183-201. [CrossRef]

68. Hausenblas, H.A.; Fallon, E.A. Relationship among body image, exercise behavior, and exercise dependence symptoms. Int. J. Eat. Disord. 2002, 32, 179-185. [CrossRef]

69. Kovacsik, R.; Griffiths, M.D.; Pontes, H.M.; Soós, I.; De La Vega, R.; Ruíz-Barquín, R.; Demetrovics, Z.; Szabó, A. The Role of Passion in Exercise Addiction, Exercise Volume, and Exercise Intensity in Long-term Exercisers. Int. J. Ment. Health Addict. 2018, 17, 1389-1400. [CrossRef]

70. Terry, A.; Szabo, A.; Griffiths, M. The exercise addiction inventory: A new brief scanning tool. Addict. Res. Theory 2004, 12, 489-499. [CrossRef]

71. Rosenberg, M. Society and the Adolescent Self-Image; Princeton University Press: Princeton, NJ, USA, 1965.

72. Moksnes, U.K.; Espnes, G.A. Self-esteem and life satisfaction in adolescents-Gender and age as potential moderators. Qual. Life Res. 2013, 22, 2921-2928. [CrossRef] [PubMed]

73. Cohen, S.; Kamarck, T.; Mermelstein, R. A global measure of perceived stress. J. Health Soc. Behav. 1983, 24, 385-396. [CrossRef] [PubMed]

74. Nielsen, M.G.; Ørnbøl, E.; Vestergaard, M.; Bech, P.; Larsen, F.B.; Lasgaard, M.; Christensen, K.S. The construct validity of the Perceived Stress Scale. J. Psychosom. Res. 2016, 84, 22-30. [CrossRef]

75. Godin, G. The Godin-Shephard leisure-time physical activity questionnaire. Health Fit. J. Can. 2011, 4, 18-22. [CrossRef]

76. Kjelsås, E.; Augestad, L.B.; Götestam, K.G. Exercise Dependence in Physically Active Women. Eur. J. Psychiatry 2003, 17, 145-155.

77. Griffiths, M. Exercise Addiction: A Case Study. Addict. Res. 1997, 5, 161-168. [CrossRef]

78. Webster, J.; Tiggemann, M. The Relationship between Women's Body Satisfaction and Self-Image across the Life Span: The Role of Cognitive Control. J. Genet. Psychol. 2003, 164, 241-252. [CrossRef] [PubMed]

79. Tiggemann, M.; Lynch, J.E. Body image across the life span in adult women: The role of self-objectification. Dev. Psychol. 2001, 37, 243-253. [CrossRef] [PubMed]

80. Tiggemann, M.; Williamson, S. The Effect of Exercise on Body Satisfaction and Self-Esteem as a Function of Gender and Age. Sex Roles 2000, 43, 119-127. [CrossRef]

81. Striegel-Moore, R.H.; Bulik, C.M. Risk factors for eating disorders. Am. Psychol. 2007, 62, 181-198. [CrossRef] [PubMed]

82. Furnham, A.; Badmin, N.; Sneade, I. Body Image Dissatisfaction: Gender Differences in Eating Attitudes, Self-Esteem, and Reasons for Exercise. J. Psychol. 2002, 136, 581-596. [CrossRef] [PubMed]

83. Arem, H.; Moore, S.C.; Patel, A.; Hartge, P.; De Gonzalez, A.B.; Visvanathan, K.; Linet, M.S. Leisure time physical activity and mortality: A detailed pooled analysis of the dose-response relationship. JAMA Intern. Med. 2015, 175, 959-967. [CrossRef]

84. Kim, Y.S.; Park, Y.S.; Allegrante, J.; Marks, R.; Ok, H.; Cho, K.O.; Garber, C.E. Relationship between physical activity and general mental health. Prev. Med. 2012, 55, 458-463. [CrossRef]

85. Lindwall, M.; Palmeira, A. Factorial Validity and Invariance Testing of the Exercise Dependence Scale-Revised in Swedish and Portuguese Exercisers. Meas. Phys. Educ. Exerc. Sci. 2009, 13, 166-179. [CrossRef]

86. Blaydon, M.J.; Lindner, K.J.; Kerr, J.H. Metamotivational characteristics of eating-disordered and exercise-dependent triathletes: An application of reversal theory. Psychol. Sport Exerc. 2002, 3, 223-236. [CrossRef]

87. Szabo, A.; Griffiths, M.D.; Marcos, R.D.L.V.; Mervó, B.; Demetrovics, Z. Focus: Addiction: Methodological and conceptual limitations in exercise addiction research. Yale J. Biol. Med. 2015, 88, 303.

88. Cheng, C.-Y. Acculturation and Cultural Value Orientations of Immigrant Chinese Americans: Effects on Body Image, Aesthetics for Appearance, and Involvement in Dress. Ph.D. Thesis, Iowa State University, Ames, IA, USA, 2018.

89. Dotse, J.E.; Asumeng, M. Relationship between Body Image Satisfaction and Psychological Well-Being: The Impact of Africentric Values. J. Soc. Sci. Stud. 2014, 2, 320. [CrossRef]

90. Portney, L.G.; Gross, L.; Watkins, M.P. Foundations of Clinical Research: Applications to Practice; EE. UU: Davis Company: Boston, MA, USA, 2015.

91. Smith-Jackson, T.; Reel, J.J.; Thackeray, R. Coping with "Bad Body Image Days": Strategies from first-year young adult college women. Body Image 2011, 8, 335-342. [CrossRef]

92. Sibley, B.A.; Hancock, L.; Bergman, S.M. University Students' Exercise Behavioral Regulation, Motives, and Physical Fitness. Percept. Mot. Skills 2013, 116, 322-339. [CrossRef] [PubMed] 
93. De La Vega, R.; Parastatidou, I.S.; Ruíz-Barquín, R.; Szabo, A.D. Exercise Addiction in Athletes and Leisure Exercisers: The Moderating Role of Passion. J. Behav. Addict. 2016, 5, 325-331. [CrossRef] [PubMed]

94. Hausenblas, H.A.; Downs, D.S. Exercise Dependence Scale-21 Manual. 2002. Available online: http://www.personal.psu.edu/ dsd11/EDS/EDS21Manual.pdf (accessed on 20 April 2021). 